\title{
Radionuclide activity concentrations in two species of reptiles from the Chernobyl exclusion zone
}

\author{
C.L. Barnett ${ }^{1}$, S. Gaschak ${ }^{2}$, N.A. Beresford ${ }^{1}$, \\ B.J. Howard ${ }^{1}$ and A. Maksimenko ${ }^{2}$ \\ ${ }^{1}$ Centre for Ecology \& Hydrology, CEH-Lancaster, Lancaster Environment Centre, Library \\ Av., Bailrigg, LA1 4AP Lancaster, UK \\ ${ }^{2}$ International Radioecology Laboratory, Slavutych, Ukraine \\ e-mail: clb@ceh.ac.uk
}

\begin{abstract}
Assessments of radiation exposure of reptiles may be required in some countries as many species are protected. However, there are few data available for the transfer of radionuclides to them, especially in terrestrial ecosystems, and consequently, no specific peer reviewed reptile data have been used in the derivation of default transfer parameters in the ERICA Tool. Twenty samples of Lacerta agilis (sand lizard) and five of Natrix natrix (grass snake) were collected from two sites within the Chernobyl Exclusion Zone and analysed for Pu-isotopes, ${ }^{137} \mathrm{Cs}$ and ${ }^{90} \mathrm{Sr}$. Corresponding activity concentrations for soil from the sampling sites were available. These data have been used to derive concentration ratios (CR) (i.e. reptile whole-body fresh weight activity concentration relative to the dry weight activity concentration in soil). CR values for $N$. natrix tended to be lower than those for $L$. agilis. The CR values derived in this paper will be used to improve the default values provided within the ERICA Tool. Whole-body activity concentrations determined in the reptile samples were broadly comparable with data available from the same sampling sites for small mammal species.
\end{abstract}

\section{INTRODUCTION}

Various models/tools have been developed to assess radiation exposure to wildlife [1]. Assessments of radiation exposure of reptiles may be required in some countries because many species are protected (e.g. [2]). However, there are few data for the transfer of radionuclides to reptile species, especially in terrestrial environments. For example, in the derivation of default transfer parameters for the ERICA Tool $[3,4]$ no published data were found within the refereed literature, although data were available for $\mathrm{Sr}$ and $\mathrm{Cs}$ from unpublished sources some of which have since been published [5].

In this paper, we present ${ }^{137} \mathrm{Cs},{ }^{90} \mathrm{Sr}$ and ${ }^{238 / 239 / 240} \mathrm{Pu}$ activity concentrations, and concentration ratios (as used in a number of assessment models), for two species of reptiles Lacerta agilis (sand lizard) and Natrix natrix (grass snake) sampled from terrestrial ecosystems within the Chernobyl Exclusion Zone (Ukraine).

\section{MATERIALS AND METHODS}

\subsection{Site description and sampling}

Over a seven year sampling period (2000 to 2007) samples of L. agilis and N. natrix were trapped at two sites: 'Red Forest' 1 and 'Red Forest' 2. Site 'Red Forest' 1 (E 30.06188, N 51.38427) was approximately $2.6 \mathrm{~km}$ south west from the Chernobyl nuclear power plant; trapping occurred over a triangular area of circa $0.15 \mathrm{~km}^{2}$. Site 'Red Forest' 2 (E 30.06405, N 51.38095) was approximately $2.7 \mathrm{~km}$ south west from the Chernobyl nuclear power plant; and trapping occurred over a square shaped area of circa $0.01 \mathrm{~km}^{2}$. 
Soil samples $(0-10 \mathrm{~cm})$ were available from measurement campaigns conducted by the Ukrainian co-authors. At 'Red Forest' 1, 345 soil cores were collected in June 2001 [6] whereas at 'Red Forest' 2, four soil cores were collected in May 2007.

A total of twenty L. agilis and five $N$. natrix were obtained (see Table 1). L. agilis were caught in 'Shermann traps' during sampling campaigns to capture small rodents. $N$. natrix were caught by hand.

\subsection{Analytical methods}

Reptile samples were stored frozen. Prior to analyses the gastrointestinal tract was removed and the remaining carcass washed. Soils were oven dried and homogenised prior to analyses.

\subsubsection{Cs and $\mathrm{Sr}$ in reptiles}

The whole-body ${ }^{137} \mathrm{Cs}$ and ${ }^{90} \mathrm{Sr}$ content in the reptiles was determined using the method described and validated by Bondarkov et al. [7, 8]. The animals were placed in a small, disposable, cardboard box $(70 \times 40 \times 40 \mathrm{~mm})$ the upper side of which was made from $<0.1 \mathrm{~mm}$ thick polyethylene. The box was then placed inside a lead shielded counting container. The detectors comprised a hyperpure germanium detector and thin-film $(0.1 \mathrm{~mm}) \mathrm{NaI}$ scintillation detector to measure ${ }^{137} \mathrm{Cs}$ and ${ }^{90} \mathrm{Sr}$ respectively. The spectra were analysed using the Canberra Genie 2000 software package to determine the activity concentration of ${ }^{137} \mathrm{Cs}$. The activity concentration of ${ }^{90} \mathrm{Sr}$ was determined from that of its daughter nuclide, ${ }^{90} \mathrm{Y}$.

\subsubsection{Cs soils}

Soil samples were analysed on Canberra hyper-pure germanium detectors and spectra were analysed using the Canberra Genie 2000 software package to determine the activity concentration of ${ }^{137} \mathrm{Cs}$. Count times were such that a counting error of $<20 \%$ on the ${ }^{40} \mathrm{~K}$ estimate was achieved.

\subsubsection{Sr soils}

Strontium-90 activity concentrations in soils were determined in sub-samples via the measurement of ${ }^{90} \mathrm{Y}$ activity concentrations using a thin-film $(0.1 \mathrm{~mm}) \mathrm{NaI}$ scintillation detector as described by Bondarkov et al. [7, 8].

\subsubsection{Pu reptiles}

Activity concentrations of ${ }^{238} \mathrm{Pu}$ and ${ }^{239,240} \mathrm{Pu}$ in reptiles were determined using standard radiochemical separation techniques. Samples were initially dissolved in $65 \% \mathrm{HNO}_{3}$ and ${ }^{242} \mathrm{Pu}$ was added as a yield tracer. Following anion exchange separation (Bio Rad AG $1 \times 8$, 100-200 mesh) and co-precipitation the samples were counted using a planar ion implanted silicon detector.

\subsubsection{Pu soils}

The ${ }^{238 / 239 / 240} \mathrm{Pu}$ activity concentrations in soils were determined using the method described and validated by Bondarkov et al. [9]. This method is based on measurement of the $\mathrm{L}_{x}$-radiation (13-23 keV) emitted from excited uranium daughter isotopes following the $\alpha$-decay of ${ }^{238-240} \mathrm{Pu}$. The method includes an absorption correction based on the self-absorption of $\mathrm{K}_{\mathrm{x}}$-radiation of barium $(32-37 \mathrm{keV})$ which is a daughter isotope of ${ }^{137} \mathrm{Cs}$. 


\section{RESULTS}

Table 1 presents radionuclide activity concentrations in soil samples; activity concentrations determined in reptile samples are presented in Table 2. Note that although ${ }^{238} \mathrm{Pu}$ and ${ }^{239 / 240} \mathrm{Pu}$ were measured separately in reptile samples, for comparison to soil results, these are reported as total ${ }^{238 / 239 / 240} \mathrm{Pu}$ activity concentrations. Mean $( \pm \mathrm{SD})$ live weights of $N$. natrix and L. agilis were $110 \pm 25 \mathrm{~g}$ and $11 \pm 3.3 \mathrm{~g}$ respectively.

Table 1. Radionuclide activity concentration (mean $\pm \mathrm{SD})\left(\mathrm{kBq} \mathrm{kg}^{-1}\right.$ dry weight $\left.(\mathrm{DW})\right)$ in $0-10 \mathrm{~cm}$ soil samples.

\begin{tabular}{lllll}
\hline Site & $\mathbf{n}$ & ${ }^{\mathbf{1 3 7}} \mathbf{C s}$ & ${ }^{\mathbf{9 0}} \mathbf{S r}$ & ${ }^{\mathbf{2 3 8} / \mathbf{2 3 9} / \mathbf{2 4 0}} \mathbf{P u}$ \\
\hline 'Red Forest' 1 & 345 & $1600 \pm 1420$ & $780 \pm 660$ & $27 \pm 39$ \\
'Red Forest' 2 & 4 & $1160 \pm 710$ & $570 \pm 230$ & $19 \pm 8.3$ \\
\hline Izumrudnoe $^{+}$ & 29 & $7.7 \pm 3.6$ & n/a & n/a \\
Gluboky Lake $^{+}$ & 32 & $70 \pm 30$ & n/a & n/a \\
\hline
\end{tabular}

${ }^{+}$Unpublished data from additional sites within the Chernobyl Exclusion Zone (T.K. Oleksyk pers. comm.).

Table 2. Whole-body activity concentrations (fresh weight (FW)) in reptiles (Mean \pm SD and range).

\begin{tabular}{|c|c|c|c|c|c|c|}
\hline Site & Sampling time & Species & $\mathbf{n}$ & $\begin{array}{l}{ }^{137} \mathrm{Cs} \\
\mathrm{kBq} \mathrm{kg}^{-1}\end{array}$ & $\begin{array}{l}{ }^{90} \mathrm{Sr} \\
\mathrm{kBq} \mathrm{kg}{ }^{-1}\end{array}$ & $\begin{array}{l}238 / 239 / 240 \\
\mathrm{~Bq} \mathrm{~kg}^{-1}\end{array}$ \\
\hline \multirow[t]{2}{*}{ 'Red Forest' 1} & Jul-Aug 2000 & L. agilis & 2 & 610 & 360 & 3.5 \\
\hline & & & & $230-990$ & $230-490$ & $2.8-4.3$ \\
\hline \multirow[t]{2}{*}{ 'Red Forest' 1} & May-Jul 2001 & L. agilis & 8 & $480 \pm 250$ & $500 \pm 320$ & $15 \pm 20$ \\
\hline & & & & $180-950$ & $69-1140$ & $3.7-62$ \\
\hline 'Red Forest' 1 & Aug 2003 & L. agilis & 1 & 460 & 610 & 3.6 \\
\hline \multirow[t]{2}{*}{ 'Red Forest' 1} & May 2007 & N. natrix & 2 & 290 & 140 & 1.6 \\
\hline & & & & $120-450$ & $92-180$ & $0.28-2.8$ \\
\hline \multirow[t]{2}{*}{ 'Red Forest' 2} & May-Jul 2003 & L. agilis & 9 & $870 \pm 410$ & $630 \pm 310$ & $6.2 \pm 8.4$ \\
\hline & & & & $140-1350$ & $330-1300$ & $0.89-28$ \\
\hline \multirow[t]{2}{*}{ 'Red Forest' 2} & May 2007 & N. natrix & 3 & $220 \pm 98$ & $170 \pm 76$ & $1.7 \pm 1.1$ \\
\hline & & & & $10-28$ & $84-230$ & $0.73-2.9$ \\
\hline \multirow[t]{2}{*}{ Izumrudnoe $^{+}$} & July-Sep 1999 & L. agilis & 10 & $4.0 \pm 2.9$ & & \\
\hline & & & & $1.7-12$ & $\mathrm{n} / \mathrm{a}$ & $\mathrm{n} / \mathrm{a}$ \\
\hline \multirow[t]{2}{*}{ Gluboky Lake $^{+}$} & July-Sep 1999 & L. agilis & 10 & $30 \pm 24$ & & \\
\hline & & & & $7.0-73$ & $\mathrm{n} / \mathrm{a}$ & $\mathrm{n} / \mathrm{a}$ \\
\hline
\end{tabular}

${ }^{+}$Unpublished data from additional sites within the Chernobyl Exclusion Zone (T.K. Oleksyk pers. comm.).

\section{DISCUSSION}

In addition to the results from the sampling described here, Table 2 presents whole-body ${ }^{137}$ Cs activity concentrations for L. agilis from two additional sites within the Chernobyl Exclusion Zone (Table 1 also includes soil activity concentrations for these sites; T.K. Oleksyk pers. comm.). Many of the assessment models [1] proposed for use to estimate the exposure of wildlife to ionising radiation use concentration ratios (CR) to estimate whole-body activity concentrations in organisms from those in soil (or other media), where $\mathrm{CR}$ is defined as:

$$
\mathrm{CR}=\frac{\text { Activity concentration in biota whole-body }\left(\mathrm{Bq} \mathrm{kg}^{-1} \mathrm{FW}\right)}{\text { Activity concentration in soil }\left(\mathrm{Bq} \mathrm{kg}{ }^{-1} \mathrm{DW}\right)}
$$


Table 3 presents estimated CR values for ${ }^{137} \mathrm{Cs}$, ${ }^{90} \mathrm{Sr}$ and ${ }^{238 / 239 / 240} \mathrm{Pu}$ for L. agilis and N. natrix sampled as part of this study; for the purposes of estimating the CR values activity concentrations of reptile samples were decay corrected to the date of soil sampling. Values for ${ }^{137} \mathrm{Cs}$ for the L. agilis samples from Izumrudnoe and Gluboky Lake have also been estimated; the CR values are similar to those calculated for 'Red Forest' 1 and 2.

Table 3. Fresh weight $\mathrm{CR}$ values for reptiles (mean $\pm \mathrm{SD}$ and/or range). For comparison default $\mathrm{CR}$ values from the ERICA Tool for reptiles and mammals are also presented.

\begin{tabular}{|c|c|c|c|c|c|c|}
\hline Site & $\begin{array}{l}\text { Sampling } \\
\text { time }\end{array}$ & Species & $\mathbf{n}$ & ${ }^{137} \mathrm{Cs}$ & ${ }^{90} \mathrm{Sr}$ & ${ }^{238 / 239 / 240} \mathrm{Pu}$ \\
\hline 'Red Forest' 1 & Jul-Aug 2000 & L. agilis & 2 & $0.143-0.620$ & $0.299-0.622$ & $(1.01-1.55) \times 10^{-4}$ \\
\hline 'Red Forest' 1 & May-Jul 2001 & L. agilis & 8 & $0.300 \pm 0.309$ & $0.642 \pm 0.682$ & $(5.48 \pm 10.5) \times 10^{-4}$ \\
\hline 'Red Forest' 1 & Aug 2003 & L. agilis & 1 & 0.275 & 0.740 & $1.32 \times 10^{-4}$ \\
\hline 'Red Forest' 1 & May 2007 & N. natrix & 2 & $0.074-0.283$ & $0.117-0.288$ & $(0.10-1.03) \times 10^{-4}$ \\
\hline 'Red Forest' 2 & May-Jul 2003 & L. agilis & 9 & $0.815 \pm 0.625$ & $1.21 \pm 0.764$ & $(3.24 \pm 4.66) \times 10^{-4}$ \\
\hline 'Red Forest' 2 & May 2007 & N. natrix & 3 & $0.187 \pm 0.142$ & $0.296 \pm 0.177$ & $(8.83 \pm 7.02) \times 10^{-5}$ \\
\hline Izumrudnoe & Aug-Sep 1999 & L. agilis & 10 & $0.512 \pm 0.373$ & - & - \\
\hline Gluboky Lake & Aug-Sep 1999 & L. agilis & 10 & $0.431 \pm 0.346$ & - & - \\
\hline \multicolumn{2}{|c|}{ Overall weighted mean } & & & $\mathbf{0 . 4 7} \pm \mathbf{0 . 4 3}$ & $0.36 \pm 0.63$ & $(3.2 \pm 6.6) \times 10^{-4}$ \\
\hline Current & $\mathrm{n} / \mathrm{a}$ & Reptile & $\mathrm{n} / \mathrm{a}$ & $3.59 \pm 9.91$ & $11.8 \pm 23.5$ & $\mathrm{n} / \mathrm{a}^{+}$ \\
\hline ERICA-Tool & & & & $0.06-28.1^{*}$ & $0.008-47^{*}$ & $(2.34 \pm 8.13) \times 10^{-2}$ \\
\hline Current & $\mathrm{n} / \mathrm{a}$ & Mammals & $\mathrm{n} / \mathrm{a}$ & $2.87 \pm 4.25$ & $1.74 \pm 2.35$ & \\
\hline ERICA-Tool & & & & $0.001-137$ & $0.001-11.9$ & $\begin{array}{l}4.53 \times 10^{-4} \\
-3.17 \times 10^{-1}\end{array}$ \\
\hline
\end{tabular}

${ }^{+}$The default ERICA Tool CR for Pu to reptiles is assumed to be the same as for mammals (note the ERICA Tool values are those presented by Beresford et al. [3] which discusses the default terrestrial database as available in July 2007).

* See text regarding the data included in the derivation of the ERICA CR values for reptiles as presented in Beresford et al. [3].

The CR values for $N$. natrix for all three radionuclides tended to be lower than those for L. agilis although there was a smaller sample size (five compared to twenty). This may reflect the diets of the two species, the diet of $N$. natrix is often dominated by amphibians although they may also consume small mammals, birds and fish (http://www.bbc.co.uk/nature/wildfacts/). In contrast, L. agilis prey upon terrestrial invertebrate species with some consumption of plant material (http://www.bbc.co.uk/nature/wildfacts/).

Table 3 also presents weighted mean CR values (across both species) and associated standard deviations using data from all four sites within the Chernobyl Exclusion Zone; for comparison default $\mathrm{CR}$ values (including ranges) from the ERICA Tool for reptiles and mammals are also presented.

Whilst values estimated here for both ${ }^{137} \mathrm{Cs}$ and ${ }^{90} \mathrm{Sr}$ are within the range of those in the ERICA database, they are circa one-order of magnitude lower than the ERICA default values. However, the ERICA default values are highly skewed by data for L. agilis (with CR values of 28 for Cs and 47 for Sr) also sampled from the Chernobyl Exclusion Zone obtained from 'grey literature' sources [10, 11]. The values estimated here for Cs are more in agreement with those for Lacerta vivipara (common lizard) and Anguis fragilis (slow worm) from a recent study of a coastal sand dune ecosystem in the United Kingdom (this work is now described in Wood et al. [5] which constituted the remaining values in the ERICA database). For Sr, in addition to the CR value for L. agilis (of 47) the ERICA Tool default was based upon a value of 0.008 for $A$. fragilis from the same coastal sand dune study as the Cs data. As a consequence of the discrepancy between the work reported here and the previously available CR values, the derivation of the L. agilis data used in the estimation of the ERICA Tool value has been investigated and found to be in error. The recalculated CR values for this data source are 0.74 (not 28) for Cs and 0.68 (not 47) for Sr. The ERICA Tool default CR value for Pu for reptiles is assumed to 
be the same as that for mammals (see Table 3). The Pu CR values derived in this study are $2-3$ orders of magnitude lower than the default ERICA mammal CR value and are at the lower end of the range (see Table 3).

The ERICA database for reptiles will be updated in the near future to include the data from this study and to correct the original database values. In the interim, the weighted CR values for reptiles based on the data reported here and the values (corrected) from the ERICA database are: (i) Cs $-0423 \pm 0.422$; (ii) $\mathrm{Sr}-0.338 \pm 0.623$; (iii) $\mathrm{Pu}-(3.23 \pm 6.56) \times 10^{-4}$. Users of the ERICA Tool should replace the existing default values with these numbers.

Data of radionuclide activity concentrations in small mammals are available from the same sampling sites for comparison with those reported here for reptile species. In late summer of 1999 the mean ${ }^{137} \mathrm{Cs}$ activity concentrations in the muscle of small mammals ranged, dependant upon species, from approximately 3 (Sorex araneus) to 30 (Clethrionomys glareolus) $\mathrm{kBq} \mathrm{kg}^{-1}$ (FW) at the Izumrudnoe site [12] (data presented on a dry weight basis by the authors have been converted assuming a $25 \%$ dry matter content). For the Gluboky Lake site the same paper presents ${ }^{137} \mathrm{Cs}$ activity concentrations ranging from approximately 65 (S. araneus) to 360 (Microtus spp.) $\mathrm{kBq} \mathrm{kg}^{-1}(\mathrm{FW})$. The mean whole-body ${ }^{137} \mathrm{Cs}$ activity concentration across all species sampled during summer 2001 at 'Red Forest' 1 was 470 $\mathrm{kBq} \mathrm{kg}^{-1}$ (FW) (Gaschak pers. comm.). Stronium-90 whole-body activity concentrations determined in a limited number of $C$. glareolus sampled in summer 2003 at both 'Red Forest' sampling sites had geometric means of approximately $150 \mathrm{kBq} \mathrm{kg}^{-1}(\mathrm{FW})$. The activity concentrations of both ${ }^{137} \mathrm{Cs}$ and ${ }^{90} \mathrm{Sr}$ in small mammals are broadly comparable with data for reptiles presented in Table 2.

\section{References}

[1] Beresford N.A., Balonov M., Beaugelin-Seiller K., Brown J., Copplestone D., Hingston J.L., Horyna J., Hosseini A., Howard B.J., Kamboj S., Nedveckaite T., Olyslaegers G., Sazykina T., Vives i Batlle J., Yankovich T.L. and Yu C., Appl. Radiat. Isot. Available on line: doi:10.1016/j.apradiso.2008.04.009 (2008).

[2] Copplestone D., Wood M.D., Bielby S., Jones S.R., Vives i Batlle J. and Beresford N.A., Habitat regulations for Stage 3 assessments: radioactive substances authorisations (R\&D Technical Report P3-101/SP1a, Environment Agency, Bristol, 2003).

[3] Beresford N.A., Barnett C.L., Howard B.J., Scott W.A., Brown J. and Copplestone D., J. Environ. Radioact. Available on line: doi:10.1016/j.jenvrad.2008.01.020 (2008).

[4] Brown J.E., Alfonso B., Avila R., Beresford N.A., Copplestone D., Pröhl G. and Ulanovsky A., J. Environ. Radioact. Available on line: doi:10.1016/j.jenvrad.2008.01.008 (2008).

[5] Wood M.D., Marshall W.A., Beresford N.A., Jones S.R., Howard B.J., Copplestone D.C. and Leah R.T., J. Environ. Radioact. Available on line: doi:10.1016/j.jenvrad.2008.03.008 (2008).

[6] Bondarkov M.D., Gaschak S.P., Ivanov Yu.A., Maksimenko A.M., Ryabushkin A.N., Zheltonozhsky V.A., Sadovnikov L.V., Chesser R.K. and Baker R.G., "Parameters of radiation situation on the territory of the Red Forest site in the Chornobyl exclusion zone as impact factors for wild non-human species", Protection of the environment from the effects of ionizing radiation, IAEA-CN-109/100, (International Atomic Energy Authority, Vienna, 2003) pp. 196-199.

[7] Bondarkov M.D., Maximenko A.M. and Zheltonozhsky V.À., Radioprotection - colloques, 37, C1, 927-931 (2002).

[8] Bondarkov M.D., Gaschak S.P., Goryanaya Ju.A., Goryanaya A.M., Maximenko A.N., Ryabushkin O.V., Saly A.A., Shulga S.A., Chesser R.K. and Rodgers B.E., Radioprotection colloques, 37, C1, 385-390 (2002).

[9] Bondarkov M.D., Zheltonozhsky V., Sadovnikov L. and Strilchuk N., "Determining plutonium isotopes content in Chornobyl samples based on uranium characteristic Lx-radiation", International conference on radioactivity in the environment (on accompanying CD), Monaco., P. Børretzen, T. Jølle and P. Strand Eds. (2002). 
[10] Radbourne K., The effect of high radiation dose on population size and health of Clethrionomys glareolus within the Chernobyl Exclusion Zone (MSc. Thesis, University of Liverpool, 2002).

[11] Cooper K. The effect of chronic radiation on invertebrate diversity and abundance within the Chernobyl Exclusion Zone (MSc. Thesis, University of Liverpool, 2002).

[12] Oleksyk T.K., Gaschak S.P., Glenn T.C., Jagoe C.H., Peles J.D., Purdue J.R., Tsyusko O.V., Zalissky O.O. and Smith M.H., Frequency distributions of 137Cs in fish and mammal populations. J. Environ. Radioact. 61, 55-74 (2002). 